\title{
Autonomous Filling of Grain-Boundary Cavities during Creep Loading in Fe-Mo Alloys
}

\author{
S. ZHANG, H. FANG, M.E. GRAMSMA, C. KWAKERNAAK, W.G. SLOOF, \\ F.D. TICHELAAR, M. KUZMINA, M. HERBIG, D. RAABE, E. BRÜCK, \\ S. VAN DER ZWAAG, and N.H. VAN DIJK
}

\begin{abstract}
We have investigated the autonomous repair of creep damage by site-selective precipitation in a binary Fe-Mo alloy (6.2 wt pct Mo) during constant-stress creep tests at temperatures of $813 \mathrm{~K}$, $823 \mathrm{~K}$, and $838 \mathrm{~K}\left(540{ }^{\circ} \mathrm{C}, 550{ }^{\circ} \mathrm{C}\right.$, and $\left.565^{\circ} \mathrm{C}\right)$. Scanning electron microscopy studies on the morphology of the creep-failed samples reveal irregularly formed deposits that show a close spatial correlation with the creep cavities, indicating the filling of creep cavities at grain boundaries by precipitation of the $\mathrm{Fe}_{2} \mathrm{Mo}$ Laves phase. Complementary transmission electron microscopy and atom probe tomography have been used to characterize the precipitation mechanism and the segregation at grain boundaries in detail.
\end{abstract}

DOI: $10.1007 / \mathrm{s} 11661-016-3642-0$

(C) The Author(s) 2016. This article is published with open access at Springerlink.com

\section{INTRODUCTION}

MOLYBDENUM is an important alloying element for high-performance steel grades to be deployed at elevated temperatures. It is mainly used to improve the creep properties by solid-solution strengthening. ${ }^{[1-3]}$ For binary Fe-Mo alloys, several studies have been performed to determine the effect of the Mo concentration on the creep behavior at elevated temperatures, ${ }^{[4]}$ but only limited data are available on the formation of Mo-containing precipitates in these model alloys. ${ }^{[8,9]}$ In high-Cr steels containing Mo and/or W, the precipitation of the $(\mathrm{Fe}, \mathrm{Cr})_{2}(\mathrm{Mo}, \mathrm{W})$ Laves phase occurs during long-term exposure at higher temperatures. The influence of Mo on the creep properties has been interpreted exclusively in terms of solid-solution strengthening and precipitation hardening, ${ }^{[10,11]}$ without considering its

S. ZHANG, Ph.D. Student, M.E. GRAMSMA, M.Sc. Student, E. BRÜCK, Professor, and N.H. VAN DIJK, Researcher, are with the Fundamental Aspects of Materials and Energy, Faculty of Applied Sciences, Delft University of Technology, Mekelweg 15, 2629 JB Delft, The Netherlands. Contact e-mail: n.h.vandijk@tudelft.nl H. FANG, Ph.D. Student, is with the Fundamental Aspects of Materials and Energy, Faculty of Applied Sciences, Delft University of Technology, and also with the Novel Aerospace Materials Group, Faculty of Aerospace Engineering, Delft University of Technology, Kluyverweg 1, 2629 HS Delft, The Netherlands. C. KWAKERNAAK, Research Assistant, and W.G. SLOOF, Researcher, are with the Department of Materials Science and Engineering, Delft University of Technology, Mekelweg 2, 2628 CD Delft, The Netherlands. F.D. TICHELAAR, Researcher, is with the Kavli Institute of Nanoscience, National Centre for HREM, Delft University of Technology, Lorentzweg 1, 2628 CJ Delft, The Netherlands, M. KUZMINA, Ph.D. Student, M. HERBIG, Researcher, and D. RAABE, Professor, are with the MaxPlanck-Institut für Eisenforschung $\mathrm{GmbH}$, Max-Planck-Straße 1, 40237, Düsseldorf, Germany. S. VAN DER ZWAAG, Professor, is with the Novel Aerospace Materials group, Faculty of Aerospace Engineering, Delft University of Technology, Kluyverweg 1, 2629 HS Delft, The Netherlands.

Manuscript submitted January 14, 2016.

Article published online July 26, 2016 role in mediating local creep damage in the form of grain boundary pores.

Recently, Laha et al. ${ }^{[12-15]}$ have reported that creep damage can be self-healed in compositionally modified austenitic stainless steels. They attributed the enhanced creep resistance to dynamic precipitation of $\mathrm{Cu}$ and $\mathrm{BN}$ at the crack surface, preventing further growth of the creep damage. In our previous work on $\mathrm{Fe}-\mathrm{Cu}$ and $\mathrm{Fe}-\mathrm{Cu}-\mathrm{B}-\mathrm{N}$ model alloys, $\mathrm{Cu}$ precipitation at deformation-induced structural defects was indeed found to take place. ${ }^{[16,17]}$ However, the preference for $\mathrm{Cu}$ and $\mathrm{BN}$ to precipitate at open deformation-induced defects was found to be relatively weak and a high concentration of spherical $\mathrm{Cu}$ precipitates was formed homogeneously in the matrix, greatly reducing the healing potential of the $\mathrm{Cu}$ atoms initially brought into a supersaturated state.

Based on these results, we subsequently explored the self-healing potential in $\mathrm{Fe}-\mathrm{Au}$ and $\mathrm{Fe}-\mathrm{Au}-\mathrm{B}-\mathrm{N}$ model alloys. ${ }^{[18-22]}$ The choice for $\mathrm{Au}$ as the active solute was based on the fact that the solute $\mathrm{Au}$ atoms are appreciably larger than the matrix $\mathrm{Fe}$ atoms (in contrast to solute $\mathrm{Cu}$ atoms), resulting in a high nucleation barrier for precipitation within the matrix. As a result, the $\mathrm{Au}$ atoms show a strong preference to exclusively segregate at dislocations and creep cavity surfaces. We have demonstrated that $\mathrm{Fe}-\mathrm{Au}$ is an excellent model system for the self-healing of creep cavities. However, the use of $\mathrm{Au}$ as a healing agent in large-scale steel structures is unlikely for economic reasons.

In the present study, the use of a technologically more relevant alloying element, Mo, to autonomously fill creep deformation-induced grain-boundary cavities is examined for a high-purity Fe-6.2 wt pct Mo model alloy. Like $\mathrm{Au}, \mathrm{Mo}$ has a larger atomic radius compared to $\mathrm{Fe}\left(r_{\mathrm{Mo}} / r_{\mathrm{Fe}}=1.09\right)$ and satisfies the key requirements for an efficient healing agent: (i) the solutionized Mo atoms are mobile and tend to segregate from the matrix at aging temperatures around $823 \mathrm{~K}\left(550{ }^{\circ} \mathrm{C}\right)$ and 
(ii) there is a high energy barrier for nucleation of Mo-rich precipitates $\left(\mathrm{Fe}_{2} \mathrm{Mo}\right)$ in the matrix due to a large atomic misfit with respect to the bcc iron lattice.

To this aim, Mo precipitation at microscopic defect sites at grain boundaries in solutionized Fe-Mo alloys is studied by creep experiments at constant loads at temperatures of $813 \mathrm{~K}, 823 \mathrm{~K}$, and $838 \mathrm{~K}\left(540{ }^{\circ} \mathrm{C}\right.$, $550{ }^{\circ} \mathrm{C}$, and $565^{\circ} \mathrm{C}$ ). The resulting microstructure of the creep-failed samples was studied in detail by electron microscopy and atom probe tomography in order to evaluate the deposition process and the mass transport to the damage sites.

\section{EXPERIMENTAL}

The composition of the studied high-purity Fe-Mo alloy (produced by Goodfellow) is listed in Table I. The samples of dog-bone shape were cut from sheet material by spark erosion and solution treated at $1173 \mathrm{~K}$ $\left(900{ }^{\circ} \mathrm{C}\right)$ for 5 hours in evacuated silica tubes filled with 200 mbar ultrahigh purity argon. The silica tubes were subsequently dropped into water at room temperature. The average grain size before creep was $19 \mu \mathrm{m}$. According to thermodynamic calculations (THERMOCALC), the Mo is fully dissolved in the iron matrix above 1111 $\mathrm{K}\left(838^{\circ} \mathrm{C}\right)$.

Creep tests were performed using an Instron testing machine (5560 series with a $1 \mathrm{kN}$ load cell) equipped with a home-built creep test module operating at high temperatures. To avoid surface oxidation of the samples, the miniature creep tester works under high vacuum conditions $\left(<1 \times 10^{-4} \mathrm{mbar}\right)$. The dog-bone shaped samples had a gage length of $12.5 \mathrm{~mm}$ and a cross section of $3 \mathrm{~mm}^{2}$ (thickness of $0.5 \mathrm{~mm}$ and width of $6 \mathrm{~mm}$ ). The creep tests were conducted at a constant temperature of $813 \mathrm{~K}, 823 \mathrm{~K}$, and $838 \mathrm{~K}\left(540{ }^{\circ} \mathrm{C}\right.$, $550{ }^{\circ} \mathrm{C}$, and $565^{\circ} \mathrm{C}$ ) and at constant creep loads. During the experiment, the force on the sample was controlled at a constant level. The corresponding stress therefore refers to the initial stress. The homogenized solute concentration of about $6.2 \mathrm{wt}$ pct (i.e., 3.7 at. pct) Mo provides a strong chemical driving force for segregation as the equilibrium concentration of solute Mo in the matrix phase amounts to $1.4 \mathrm{wt}$ pct (i.e. 0.8 at. pct) Mo at a testing temperature of $823 \mathrm{~K}\left(550^{\circ} \mathrm{C}\right)$. The supersaturation corresponds to $4.8 \mathrm{wt}$ pct (i.e. 2.9 at. pct) Mo.

Microstructures were analyzed with a scanning electron microscope (JEOL JSM 6500F) equipped with an Autrata back-scattered electron detector and electron back-scattering diffraction (EBSD) system employing an Oxford-HKL Nordlys II detector. Micrographs were taken with electron beam energy of $15 \mathrm{keV}$. The EBSD patterns were acquired with electron beam energy of 20

Table I. The Chemical Composition of the Fe-Mo Alloy (in Weight Percent) with Balance Iron

\begin{tabular}{lccc}
\hline Mo & N & C & S \\
\hline 6.207 & 0.0047 & 0.0183 & $<0.001$ \\
\hline
\end{tabular}

$\mathrm{keV}$ and a beam current of $600 \mathrm{pA}$. Except for the analysis of the fracture surface, the microstructure analysis was performed in the uniform elongation part of the samples. Transmission electron microscopy (TEM) measurements were performed using a Tecnai F20ST/STEM instrument operating at $200 \mathrm{kV}$. Bright Field (BF), lattice images (without objective aperture), and Annular Dark Field (ADF) in STEM (Scanning Transmission Electron Microscopy) mode were obtained. ADF images show the heavier parts of the sample as bright (Z-contrast). For elemental analysis, energy-dispersive spectroscopy was performed using the attached EDAX CM-200ST system (30 $\mathrm{mm}^{2}$, ultrathin window).

The Mo enrichment at the grain boundary and the accompanying matrix depletion were studied by atom probe tomography (APT). The target preparation of specific grain boundaries into the apex of the atom probe specimens was conducted using a FEI Helios NanoLab 600i dual-beam FIB/SEM instrument. Grain boundaries that showed the features of interest were first identified by means of a 2D EBSD scan and then extracted from the surface of the bulk material by standard FIB lift-out procedures. The selected areas of interest were deposited on a commercial Si tip array and then sharpened to tip radii of $<100 \mathrm{~nm}$. After a cleaning procedure as described by Thompson, ${ }^{[23]}$ the samples were analyzed by APT. The APT characterization was conducted on a LEAP 3000X HR instrument (Cameca), operated in laser-pulsed mode at a base temperature of $60 \mathrm{~K}\left(-213^{\circ} \mathrm{C}\right)$, a laser frequency of $250 \mathrm{kHz}$, and a 0.4 $\mathrm{nJ}$ pulse energy. The reconstruction was carried out using commercial software (Cameca IVAS ${ }^{\circledR}$ ) following the protocol introduced by Geiser et al. ${ }^{[24]}$

\section{RESULTS}

\section{A. Creep at Constant Stress}

The creep results for the as-quenched (solutionized) Fe-Mo alloy loaded at different constant stress levels at a fixed temperature of $823 \mathrm{~K}\left(550{ }^{\circ} \mathrm{C}\right)$ are presented in Figure 1. The strain-time curves in Figure 1(a) indicate that this alloy shows a considerable ductility, which leads to high creep strains (>50 pct) upon fracture. The corresponding strain rate as a function of strain (Figure 1(b)) indicates a short primary creep regime where the creep rate rapidly decreases, until a more steady-state creep starts at a strain of about 0.08. From the strain versus time (Figure 1(a)) and the strain rate versus strain (Figure 1(b)), it can be seen the primary creep stage extends until a strain of about 0.08 is reached. The primary creep is followed by an oscillating creep rate before the minimum strain rate is observed. The strain rate oscillation is attributed to continuous dynamic recrystallization. ${ }^{[25-27]}$ After the steady-state creep regime, a gradual increase in creep rate takes place, which marks the start of the tertiary creep regime. The fraction of the creep lifetime occupied by the quasi steady-state creep regime decreases at higher stress levels. 
Table II. A Summary of the Creep Results for the Fe-Mo Alloy with the Creep Temperature $T$ the Creep Stress $\sigma$, the Average Grain Diameter $d$ of the Alloy, the Time to Rupture $t_{\mathrm{r}}$, the Minimum Strain Rate $\dot{\varepsilon}_{\mathrm{min}}$ and the Area Fraction of Fe $\mathrm{Fe}_{2} \mathrm{Precipitates}$ $f_{\mathrm{p}}$

\begin{tabular}{lccccc}
\hline$T \mathrm{~K}\left({ }^{\circ} \mathrm{C}\right)$ & $\sigma(\mathrm{MPa})$ & $d(\mu \mathrm{m})$ & $t_{\mathrm{r}}(\mathrm{h})$ & $\dot{\varepsilon}_{\min }\left(\times 10^{-4} \mathrm{~h}^{-1}\right)$ & $f_{p}(\mathrm{percent})$ \\
\hline $823(550)$ & 180 & 19 & 849.2 & 3.52 & $0.11 \pm 0.03$ \\
& 190 & & 311.6 & 8.04 & $0.079 \pm 0.034$ \\
$838(565)$ & 200 & & 117.0 & 25.1 & $0.036 \pm 0.011$ \\
& 160 & 28 & 715.6 & 5.47 & $0.84 \pm 0.14$ \\
$813(540)$ & 200 & & 62.4 & 31.8 & $0.31 \pm 0.11$ \\
$823(550)$ & 237 & 28 & 2.1 & 7.81 & $0.16 \pm 0.06$ \\
$838(565)$ & 200 & & 318.1 & 13.1 & $0.017 \pm 0.005$ \\
\hline
\end{tabular}

The quasi steady-state strain rate and the creep lifetime as a function of the applied stress at a temperature of $823 \mathrm{~K}\left(550{ }^{\circ} \mathrm{C}\right)$ are shown in Figures $1(\mathrm{c})$ and (d). As expected, the creep rate increases with increasing stress. The stress exponent is deduced from the Sherby-Dorn equation for the steady-state strain rate $^{[28]}$ :

$$
\dot{\varepsilon}_{s}=A d^{m} \sigma^{n} \exp \left(-\frac{Q}{R T}\right),
$$

where $A$ is a structure-dependent constant, $Q$ is an apparent activation energy, $d$ is the grain size, $m$ is the grain size exponent, $\sigma$ is the stress, and $n$ is the stress exponent. The deduced stress exponent of $n \approx 15$ is relatively high and is related to the interaction between the solute Mo atoms and the high dislocation density generated at these high-strain levels. ${ }^{[9,29]}$ The creep lifetime decreases for increasing stress with a maximum lifetime until fracture of 849 hours at the lowest applied stress of $180 \mathrm{MPa}$. In Figures 1(e) and (f), the corresponding area fraction of $\mathrm{Fe}_{2} \mathrm{Mo}$ Laves phase precipitates, obtained from an image analysis of the SEM data (described in the "Section III-B"), is shown as a function of stress and lifetime, respectively. The precipitate fraction increases with the creep life time and is still relatively low compared to the equilibrium fraction of 9.8 vol. pct $\mathrm{Fe}_{2} \mathrm{Mo}$.

The results of temperature-dependent creep tests on the solutionized Fe-Mo alloy performed at a stress of $200 \mathrm{MPa}$ and temperatures of $813 \mathrm{~K}, 823 \mathrm{~K}$, and $838 \mathrm{~K}$ $\left(540{ }^{\circ} \mathrm{C}, 550{ }^{\circ} \mathrm{C}\right.$, and $\left.565^{\circ} \mathrm{C}\right)$ are shown in Figure 2. Using Eq. [1], an experimental activation energy of $Q=$ $319 \pm 14 \mathrm{~kJ} / \mathrm{mol}$ was obtained, which is consistent with the activation energy for the diffusion of Mo in $b c c$ iron. ${ }^{[30]}$ In Figures 2(e) and (f), the corresponding area fraction of $\mathrm{Fe}_{2} \mathrm{Mo}$ Laves phase precipitates, obtained from an image analysis of the SEM data (described in the "Section III-B"), is shown as a function of temperature and lifetime, respectively. The precipitate fraction increases with temperature.

An additional set of creep tests on the same alloy, but with a different average grain size $(d=28 \mu \mathrm{m})$, was conducted at a temperature of $838 \mathrm{~K}\left(565^{\circ} \mathrm{C}\right)$ for an applied stress of 160, 200, and $237 \mathrm{MPa}$. From these experiments, the same stress exponent of $n \approx 15$ was obtained. In Table II, the quantitative results of the creep tests have been summarized.

\section{B. Scanning Electron Microscopy}

The fracture surface after creep failure for a stress of $200 \mathrm{MPa}$ and a temperature of $823 \mathrm{~K}\left(550{ }^{\circ} \mathrm{C}\right)$ is shown in Figure 3 and indicates a ductile fracture mode. Mo-rich precipitates are observed on the fracture surface, as indicated by the arrows. The phase composition was analyzed by EDS (a quantitative analysis of the phase composition is presented in the section describing the TEM and atom probe measurements).

Figure 4 shows the SEM morphology of the Fe-Mo alloy after creep failure. In Figures 4(a) and (b), the microstructure after creep at a stress of $180 \mathrm{MPa}$ and a temperature of $823 \mathrm{~K}\left(550{ }^{\circ} \mathrm{C}\right)$ is shown. The direction of the applied stress is indicated in the upper left hand corner. In the SEM picture of Figure 4(a), a majority of grains are elongated along the stress direction. Such a grain elongation is as expected for a fracture strain of about 60 pct. Mo-rich deposits are formed heterogeneously along the grain boundaries. The largest precipitates are formed at triple junctions, which are also the preferential nucleation sites for creep cavities. At high magnification (Figure 4(b)), the microstructure shows a partial filling of a microscopic defect site (1), as well as irregular-shaped precipitates that are not connected to a pore, marked by (2) and (3). These observations are explained by a preferential Mo segregation on the creep cavity surface and a continuous growth of the formed precipitates until a complete filling of the creep cavities is achieved. Figures 4(c) and (d) shows the microstructure after creep at a higher temperature of $838 \mathrm{~K}$ $\left(565^{\circ} \mathrm{C}\right.$ ) for a stress of $200 \mathrm{MPa}$. Again, heterogeneous precipitation along grain boundaries is clearly visible. Creep cavities are mainly formed along grain boundaries perpendicular to the stress direction, which are the favorite sites for cavity nucleation. However, the growth and coalescence of these cavities are relatively fast, so that the Mo may not have had sufficient time to precipitate at the cavity surface and fill the damage site completely. 


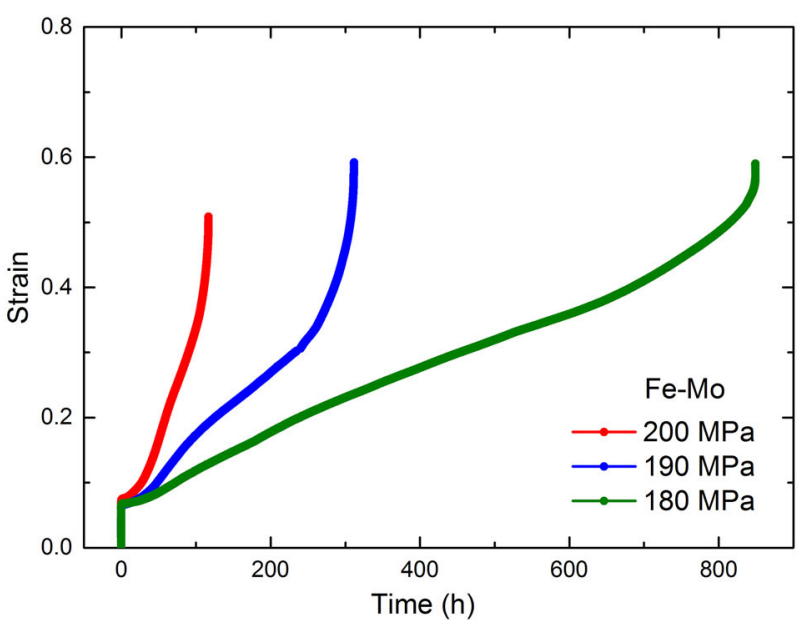

(a)

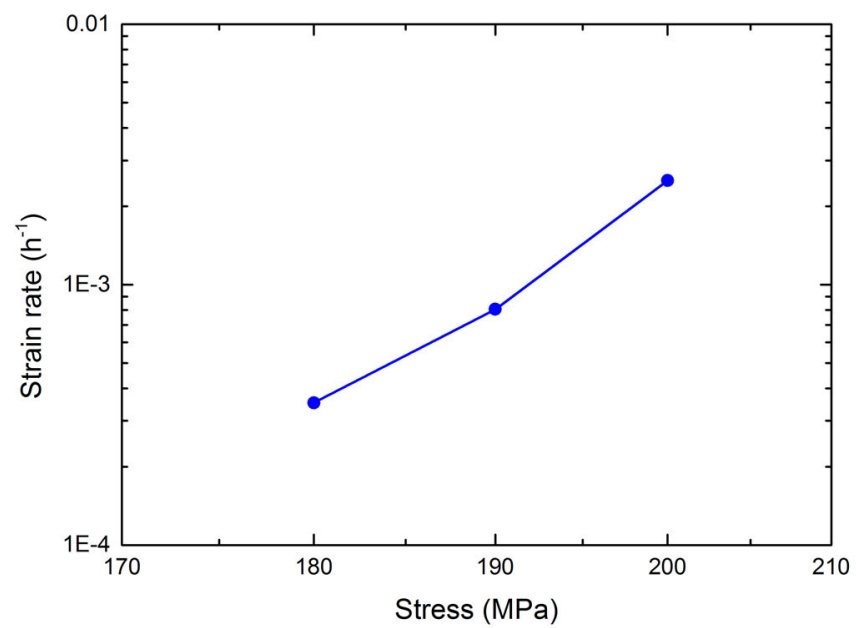

(c)

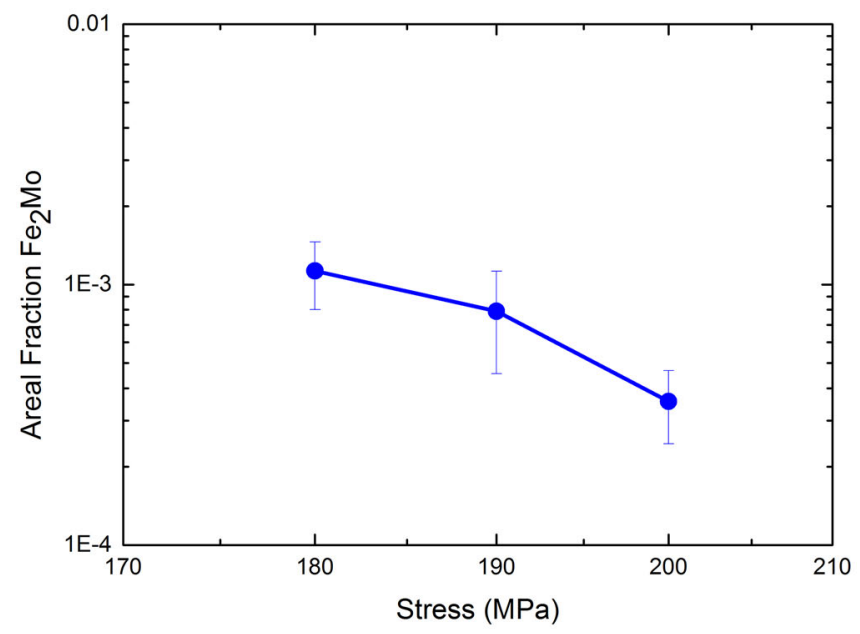

(e)

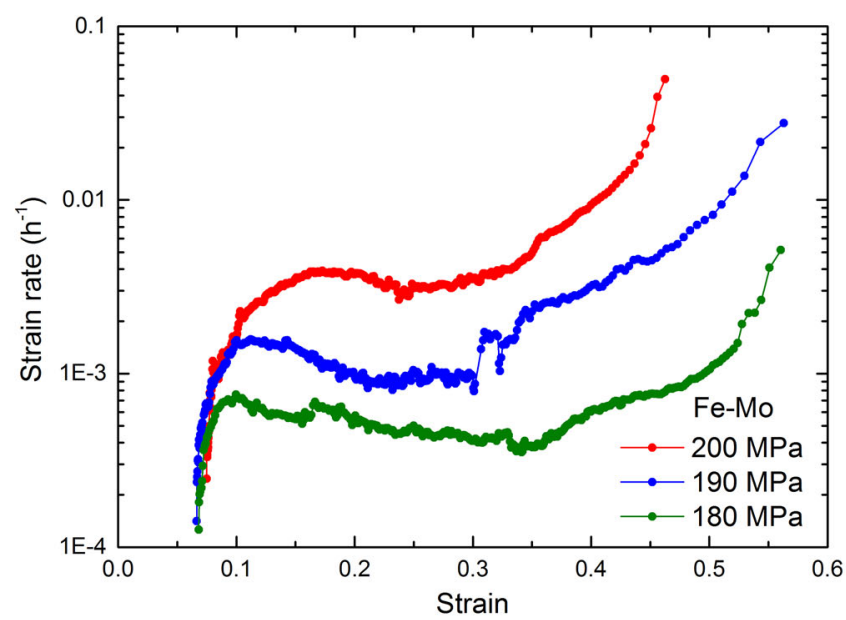

(b)

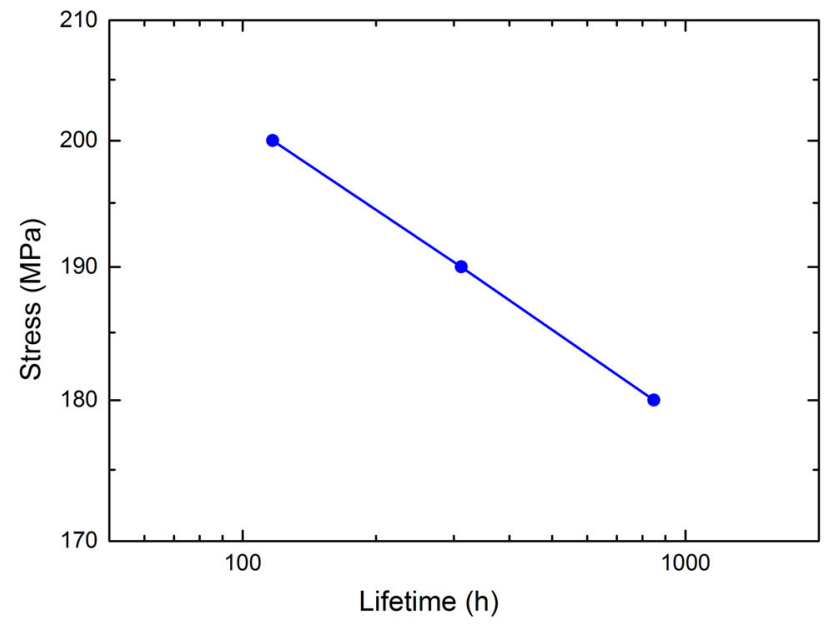

(d)

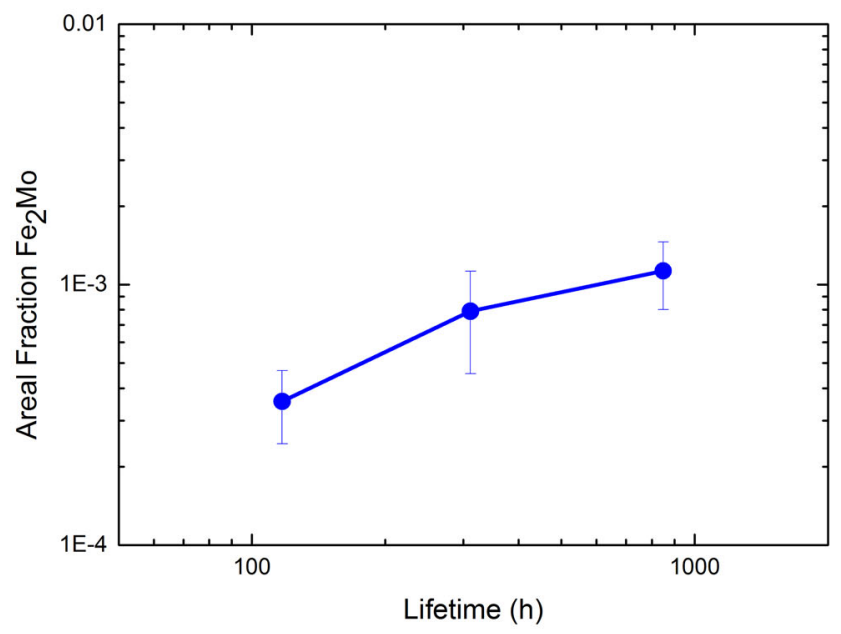

(f)

Fig. 1-(a) Creep curves for the Fe-Mo alloy for constant stress at a temperature of $823 \mathrm{~K}\left(550{ }^{\circ} \mathrm{C}\right)$ and $(b)$ the corresponding strain rate as a function of strain. From these, $(c)$ the steady-state strain rate and $(d)$ the creep lifetime as a function of applied stress are determined. From an image analysis of the SEM data, the area fraction of the $\mathrm{Fe}_{2} \mathrm{Mo}$ Laves phase is deduced as a function of $(e)$ stress and $(f)$ lifetime.

In order to observe a more pronounced interaction between the creep damage and the site-selective Mo precipitation at the free cavity surface, a lower load of
$160 \mathrm{MPa}$ was applied at the higher temperature of $838 \mathrm{~K}$ $\left(565^{\circ} \mathrm{C}\right)$. The strain at rupture reaches a relatively high value of about 60 pct for which damage is observed at 


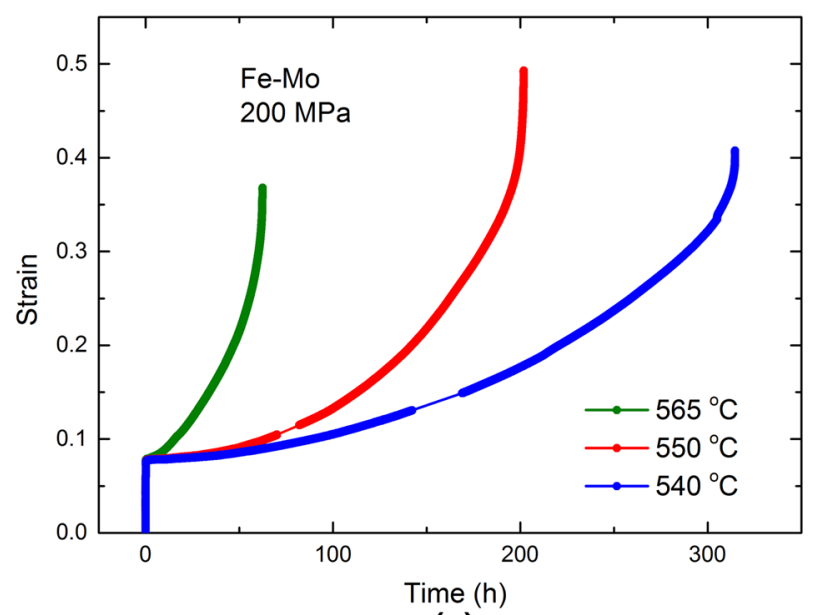

(a)

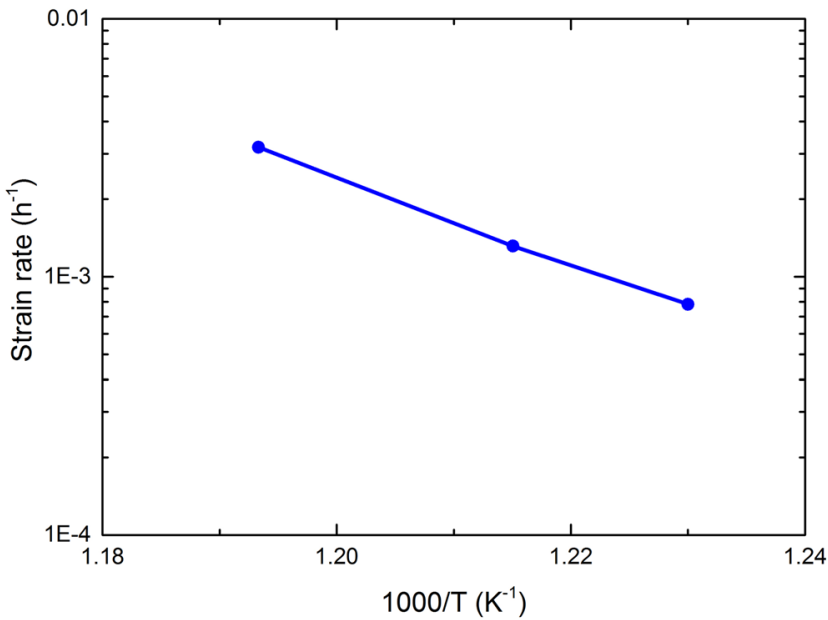

(c)

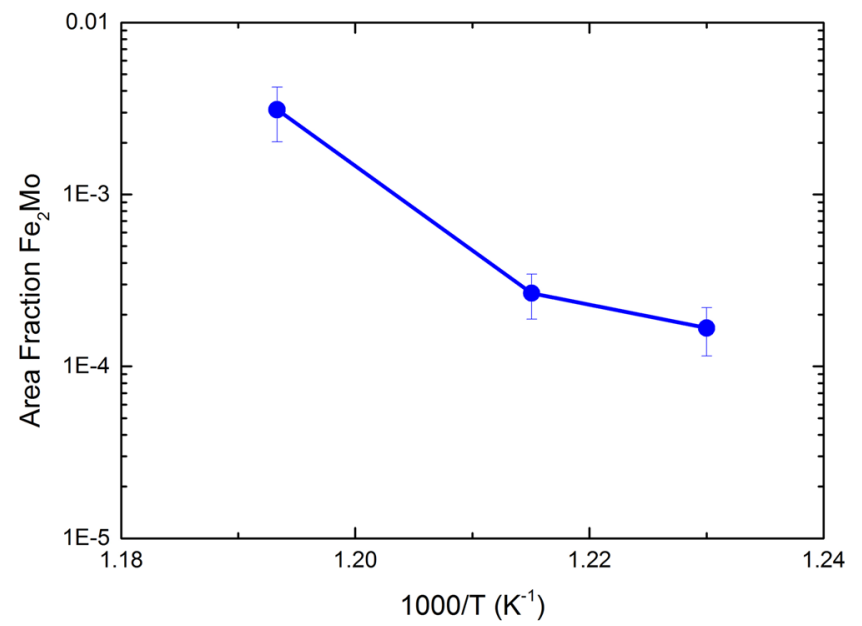

(e)

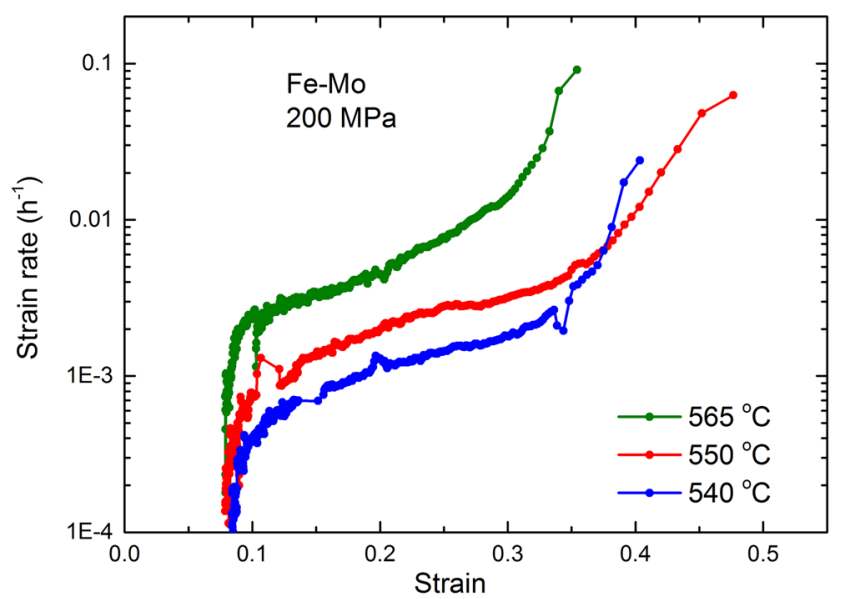

(b)

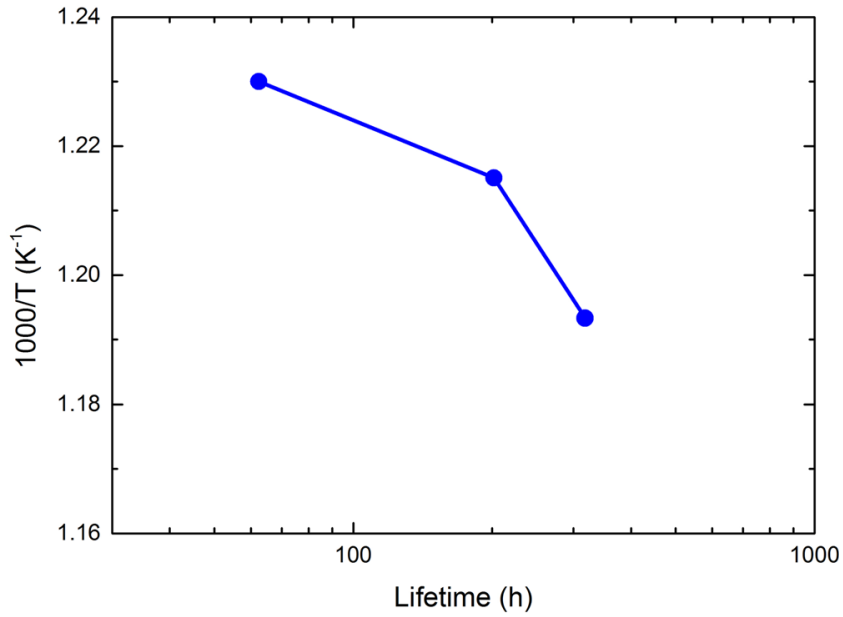

(d)

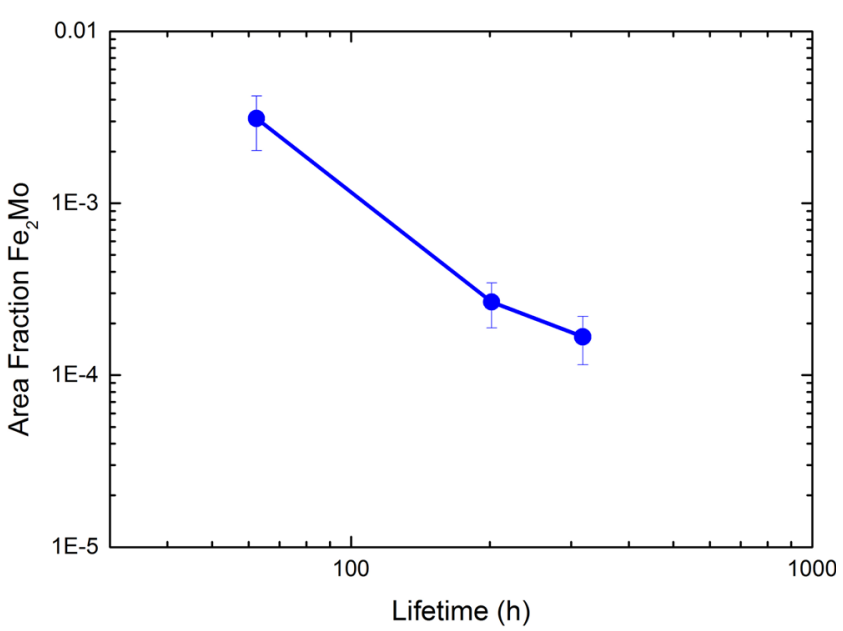

(f)

Fig. 2-(a) Creep curves and (b) strain rate as a function of strain at different temperatures for the Fe-Mo alloy at a stress of 200 MPa. Arrhenius plot illustrating the temperature dependence of $(c)$ the strain rate and $(d)$ the life time. From an image analysis of the SEM data, the area fraction of the $\mathrm{Fe}_{2} \mathrm{Mo}$ Laves phase is deduced as a function of $(e)$ temperature and $(f)$ lifetime.

(i) grain boundaries oriented perpendicular to the loading direction, (ii) triple points, and (iii) sliding grain boundaries oriented at a shallow angle to the loading direction. Figure 5 depicts the SEM images of creep damage and site-selective Mo precipitation along parallel grain boundaries. Examples of (i) unfilled cavities, 

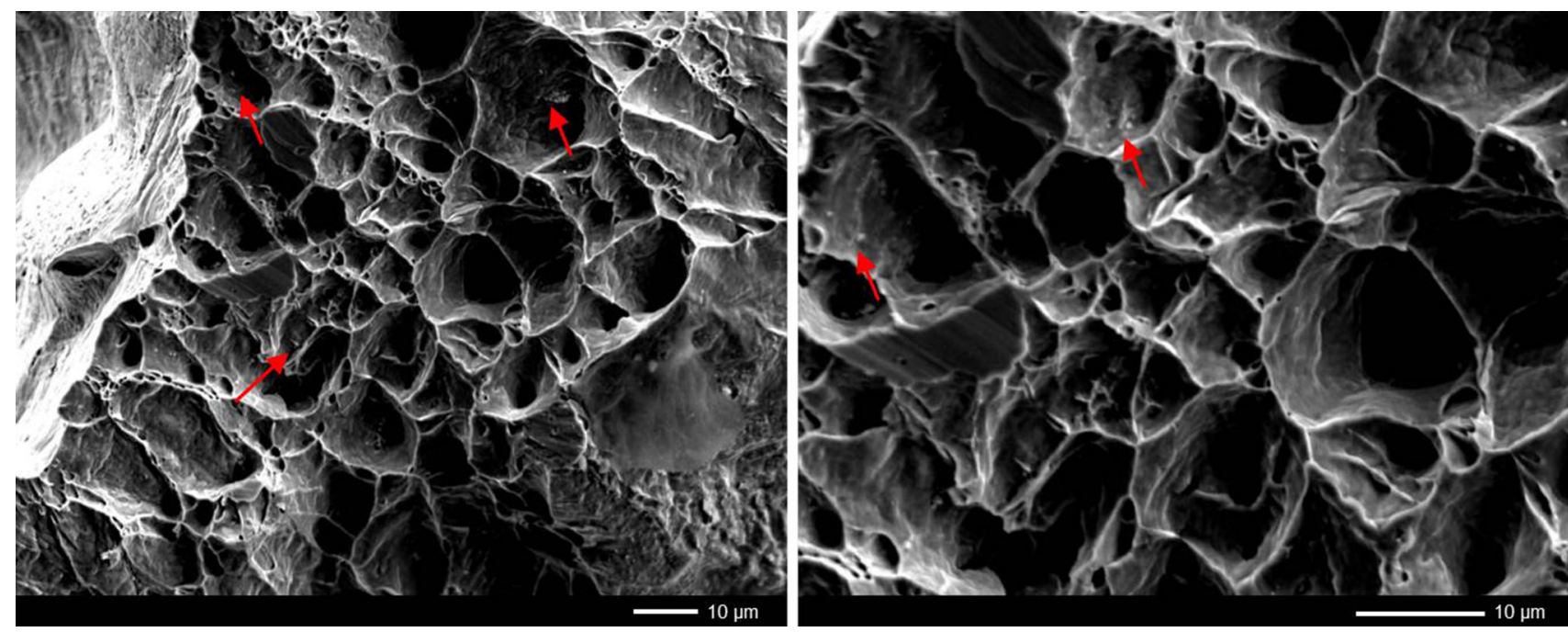

Fig. 3-Fracture surfaces of the Fe-Mo alloy after creep for an applied stress of $200 \mathrm{MPa}$ at a temperature of $823 \mathrm{~K}\left(550^{\circ} \mathrm{C}\right)$. Red arrows mark the Mo-rich precipitates (Color figure online).
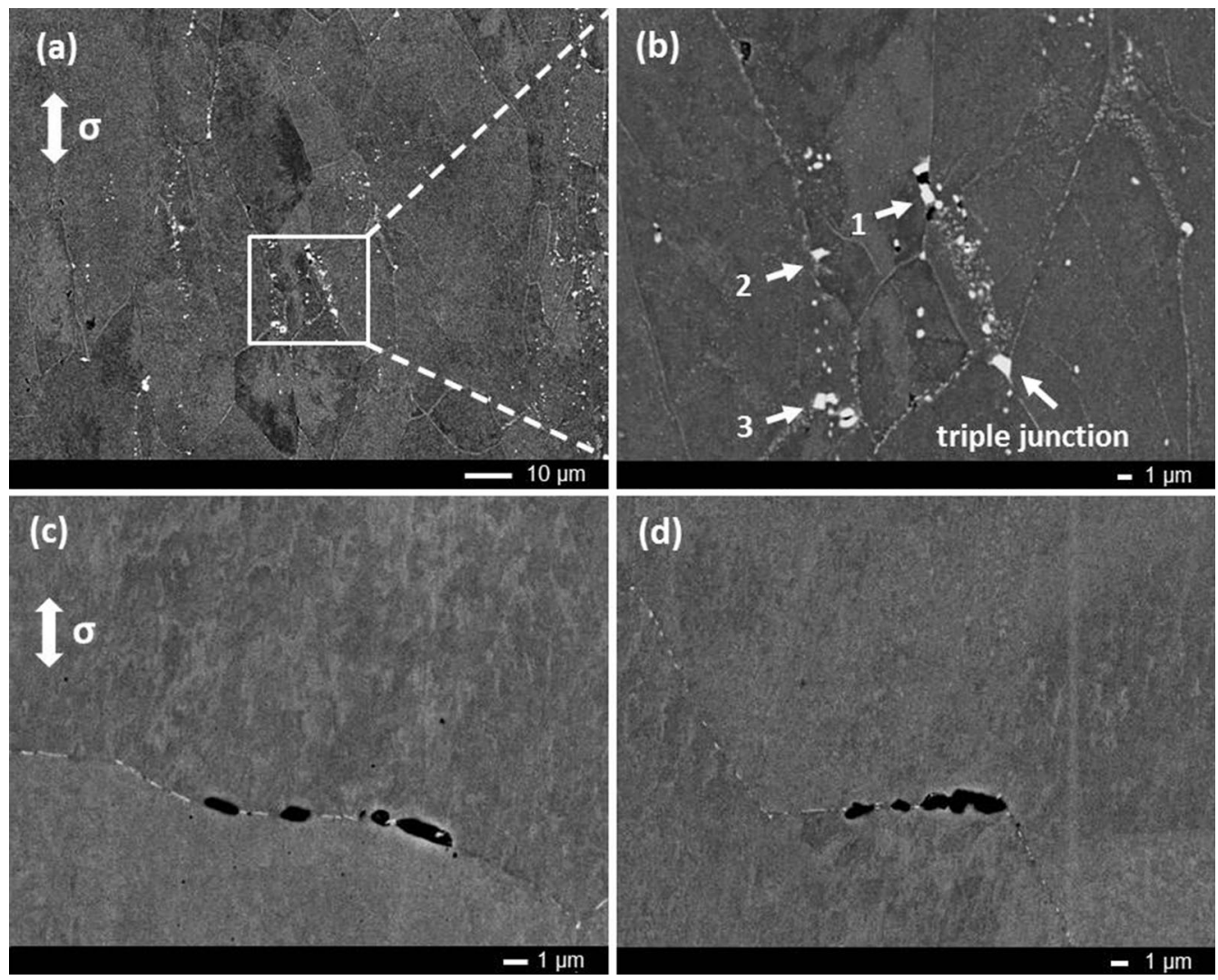

Fig. 4-Micrographs of the Fe-Mo alloy after creep for $(a, b)$ a stress of $180 \mathrm{MPa}$ at a temperature of $823 \mathrm{~K}\left(550{ }^{\circ} \mathrm{C}\right),(c, d)$ a stress of 200 $\mathrm{MPa}$ at a temperature of $838 \mathrm{~K}\left(565^{\circ} \mathrm{C}\right)$.

(ii) partially filled cavities, and (iii) fully filled cavities can clearly be observed. Creep damage and site-selective Mo precipitation are not only restricted to parallel grain boundaries, but also seem to occur in some localized deformation bands within the grains, as marked by the white arrows in Figure 5(a).
In Figure 6(a), the SEM image illustrates the creep damage and Mo precipitation observed at grain boundaries oriented perpendicular to the loading direction. The partially filled triple junction reveals a complex precipitate phase comprised of several individual crystallites. By combining a series of SEM images, the area 

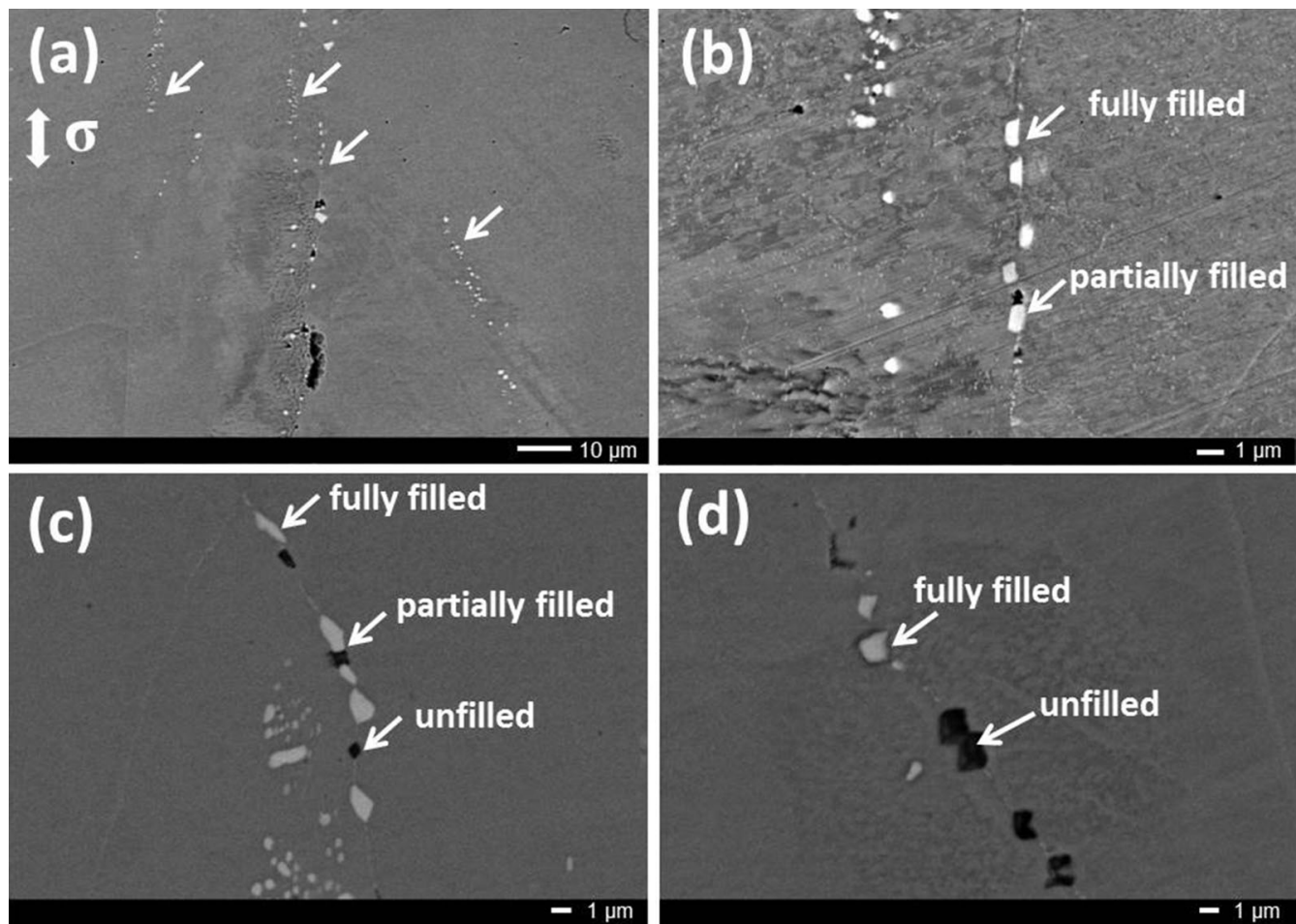

Fig. 5-Micrographs of the Fe-Mo alloy after creep for a stress of $160 \mathrm{MPa}$ at a temperature of $838 \mathrm{~K}\left(565{ }^{\circ} \mathrm{C}\right)$ demonstrating cavities and precipitation at grain boundaries parallel to the loading direction at selected locations ( $a$ to $d$ ).

fraction of $\mathrm{Fe}_{2} \mathrm{Mo}$ precipitates was obtained for the studied creep conditions. The obtained results are shown in Figures 1 and 2 and summarized in Table II.

To obtain more insight into the microstructure evolution during creep, EBSD experiments were performed. In Figure 7, orientation maps for the solutionized Fe-Mo alloy are shown (a) before and (b) after creep at a stress of $160 \mathrm{MPa}$ and a temperature of $838 \mathrm{~K}$ $\left(565^{\circ} \mathrm{C}\right)$. In contrast to earlier measurements on creep-loaded solutionized $\mathrm{Fe}-\mathrm{Au}$ alloys, ${ }^{[22]}$ no indications for an extensive subgrain formation were observed. However, the average grain size for the Fe-rich $b c c$ matrix phase derived from the EPMA figures was reduced from $33 \mu \mathrm{m}$ before creep (Figure 7(a)) to 22 $\mu \mathrm{m}$ after creep (Figure 7(b)) (in accordance with the dynamic recrystallization assumed on the basis of the oscillating creep rate). Note that the value of the grain size before creep is close to the statistically more accurately value of $28 \mu \mathrm{m}$, obtained by analyzing a series of SEM images of the same alloy. A comparison of the orientation maps before and after creep suggests that some $\langle 111\rangle$ micro-texture has formed during the creep tests. The white areas in the creep-failed sample correspond to the Laves phase $\mathrm{Fe}_{2} \mathrm{Mo}$.

\section{Transmission Electron Microscopy}

TEM measurements were performed on the Fe-Mo alloy after creep at $180 \mathrm{MPa}$ and $823 \mathrm{~K}\left(550{ }^{\circ} \mathrm{C}\right)$ to characterize the structure and composition of the precipitates formed in the grain interior and the

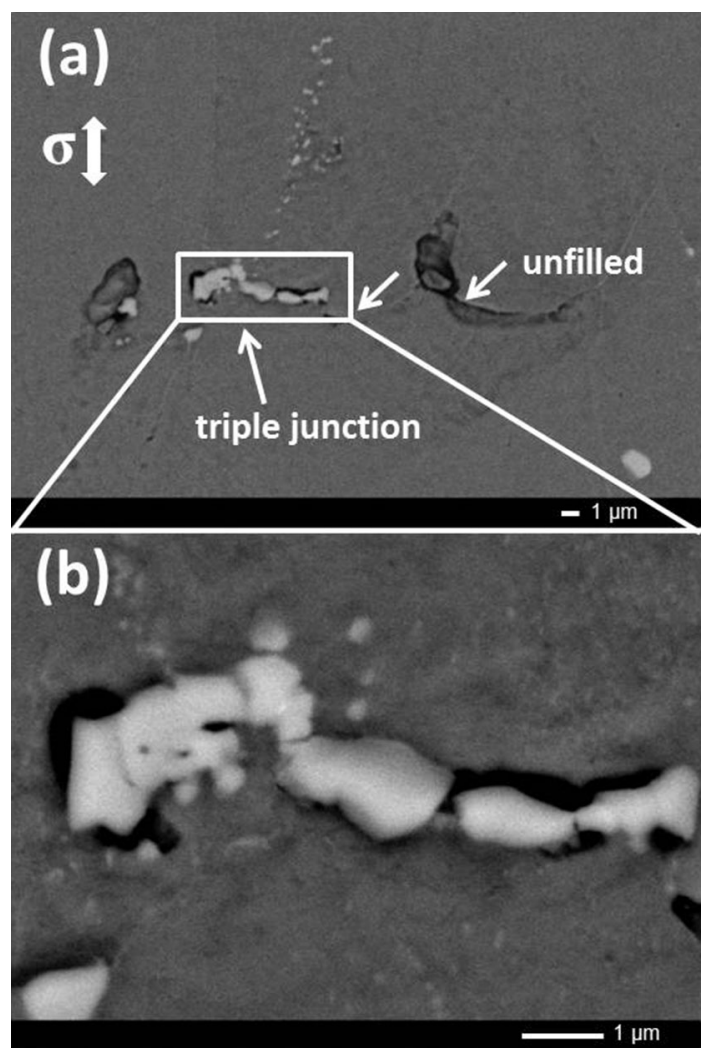

Fig. 6- (a) Micrographs of the Fe-Mo alloy after creep for a stress of $160 \mathrm{MPa}$ at a temperature of $838 \mathrm{~K}\left(565^{\circ} \mathrm{C}\right)$ demonstrating cavities and precipitation at grain boundaries perpendicular to the loading direction. (b) Enlargement of the selected region of interest shown in (a). 


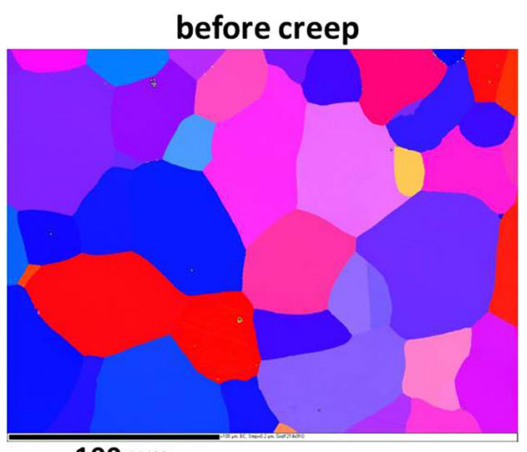

$100 \mu \mathrm{m}$

(a)

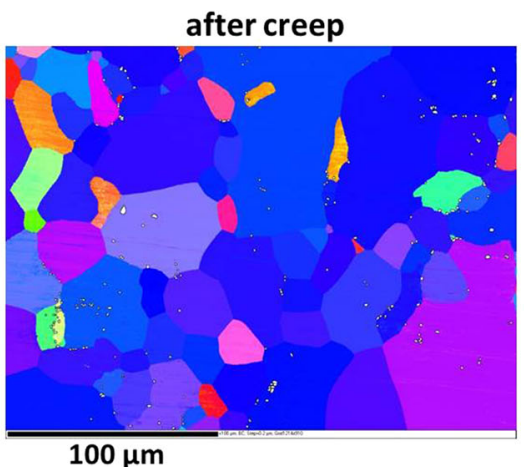

(b)

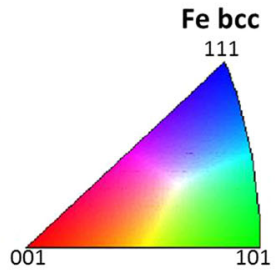

Fig. 7- Orientation maps for the solutionized Fe-Mo alloy $(a)$ before and $(b)$ after creep for a stress of $160 \mathrm{MPa}$ at a temperature of $838 \mathrm{~K}$ $\left(565{ }^{\circ} \mathrm{C}\right)$. The colors correspond to the inverse pole figure with respect to the sample surface normal. The white areas in the sample after creep correspond to the Laves phase $\mathrm{Fe}_{2} \mathrm{Mo}$.
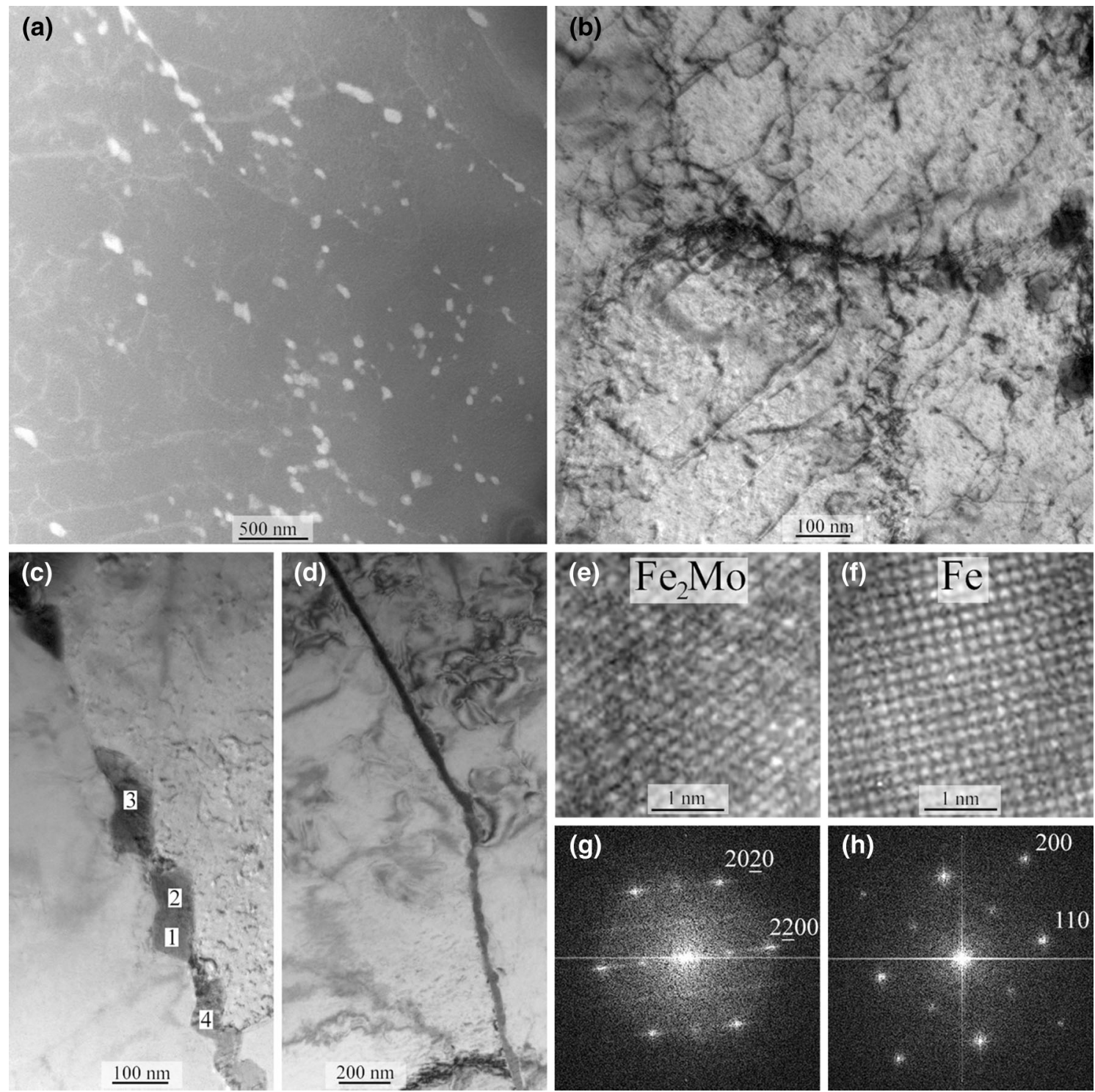

Fig. 8-TEM images of the Fe-Mo alloy after creep at $180 \mathrm{MPa}$ and $823 \mathrm{~K}\left(550{ }^{\circ} \mathrm{C}\right)$. (a) STEM annular dark field showing matrix precipitates. (b) BF showing matrix dislocations. $(c, d) \mathrm{BF}$ showing grain-boundary precipitates. $(e, f)$ HREM taken from areas near position 4 in (c) in the precipitates and the matrix, respectively. The associated Fourier transforms in $(g)$ and $(h)$ were taken from a larger area than shown in (e) and (f). 
precipitates formed at the grain-boundary cavities. As shown in Figure 8, nanoscale precipitates are formed in the matrix after creep. A high dislocation density is present due to the extensive plastic deformation during creep (Figures 8(a) and (b)). Previous TEM studies on similar model alloys (Fe-Cu, Fe-Cu-B-N, Fe-Au, and $\mathrm{Fe}-\mathrm{Au}-\mathrm{B}-\mathrm{N}$ ) did not reveal a high dislocation density for undeformed specimens that were heated to $823 \mathrm{~K}$ $\left(550{ }^{\circ} \mathrm{C}\right) \cdot{ }^{[16-18,22]}$

Precipitates are also present along grain boundaries, as shown in Figure 8(c). Some grain boundaries are completely covered with a thin film of the $\mathrm{Fe}_{2} \mathrm{Mo}$ phase (see Figure 8(d)). The nature of the precipitates and film was identified by EDS and by lattice imaging, respectively. For example, the $\mathrm{Fe}$ and Mo compositions were measured with the electron beam on four different positions on the precipitates in Figure 8(c) (see numbers) as $33( \pm 1), 33( \pm 1), 32( \pm 2)$, and 31 $( \pm 2)$ at. pct Mo, consistent with a $\mathrm{Fe}_{2} \mathrm{Mo}$-type precipitate. Several lattice images were obtained from different precipitates that showed lattice spacings and lattice-plane angles consistent with a hexagonal $\mathrm{Fe}_{2} \mathrm{Mo}$ lattice structure with $a=0.472 \mathrm{~nm}$ and $c=0.772 \mathrm{~nm}$. In thermodynamic equilibrium at a temperature of $823 \mathrm{~K}\left(550{ }^{\circ} \mathrm{C}\right)$, the presence of the $\mathrm{Fe}_{2} \mathrm{Mo}$ phase in combination with the Fe-rich $b c c$ matrix phase is expected for our binary Fe-Mo alloy. ${ }^{[31]}$ One of the lattice images covers an area of Figure 8(c) that contains precipitate number 4 and the neighboring matrix. The associated Fourier transform in Figure 8(g) shows that the electron beam was aligned along the [0001] axis of the hexagonal structure for precipitate number 4. Part of the same lattice image of the matrix neighboring precipitate number 4 is shown in Figure 8(f). The associated Fourier transform (of a larger area) in Figure 8(h) shows the electron beam direction in the Fe matrix is [100]. The indices in the Fourier transforms further indicate that within a few degrees the orientation relation $(2 \underline{200})_{\mathrm{Fe}_{2} \mathrm{Mo}} \|(110)_{\mathrm{Fe}}$ is found. Hence, for this precipitate, an orientation relationship with one of the Fe grains is approximately:

$$
\begin{gathered}
{[0001]_{\mathrm{Fe}_{2} \mathrm{Mo}} \|[100]_{\mathrm{Fe}}} \\
(2 \underline{200})_{\mathrm{Fe}_{2} \mathrm{Mo}} \|(110)_{\mathrm{Fe}}
\end{gathered}
$$

Other orientation relationships exist as well, as is to be expected for precipitates at a grain boundary.

\section{Atom Probe Tomography}

APT was employed to quantify grain-boundary segregation, the chemical composition of the Mo-rich precipitates at the grain boundaries, the matrix composition in direct contact to the grain-boundary precipitates, and the matrix composition far away from the grain boundaries. In total, six tips with a total volume of $3.5 \times 10^{6} \mathrm{~nm}^{3}$ were measured. The tips were prepared from two lift-outs, one at the grain boundary and the other in the matrix.
According to thermodynamic calculations, two phases are in equilibrium at $823 \mathrm{~K}\left(550{ }^{\circ} \mathrm{C}\right)$ in the Fe-Mo alloy investigated here: the Laves phase $\mathrm{Fe}_{2} \mathrm{Mo}$ with 33 at. pct Mo and the $\alpha$-iron matrix with 0.8 at. pct Mo. Our APT results summarized in Figure 9 indicate that the Mo concentration in the grain-boundary precipitates in the $\alpha$-iron matrix close to the grain-boundary precipitates and in the $\alpha$-iron matrix far away from the grain boundaries amount to 36, 2.0, and 3.5 at. pct Mo, respectively. The measured composition of the precipitates and the adjacent matrix is in close agreement with the predicted equilibrium values. However, the composition of the matrix further away from the grain boundaries is still close to the nominal alloy composition of 3.7 at. pet Mo, and thus far from thermodynamic equilibrium (this was also found from EDS in TEM). It can be concluded that although the system is close to local equilibrium at the precipitates, the overall system is still far away from thermodynamic equilibrium. Mo is thus still supersaturated in the matrix and available for further healing of creep defects.

Two different grain boundaries were measured and the amount of segregated solutes was analyzed by means of a 1D concentration profile and ladder diagrams. ${ }^{[32]}$ As indicated in Figure 10, the crystallographic character of the interfaces was analyzed based on the crystallographic information contained in the detector event histograms of the atom probe runs by means of atom probe crystallography. ${ }^{[33]}$ Both measured grain boundaries were identified as high-angle grain boundaries. At a grain boundary with a disorientation angle of about 16 deg, a Mo solute excess of $3.15 \mathrm{at} / \mathrm{nm}^{2}$ was measured (Figures 9(a) and (b)), while at a grain boundary with a disorientation angle of about $35 \mathrm{deg}$ a Mo excess value of $3.37 \mathrm{at} / \mathrm{nm}^{2}$ was measured (Figure 10). Such a variation in the solute excess between two different grain boundaries is normal, as the enrichment of solutes at grain boundaries is highly dependent on their crystallographic character. ${ }^{[34,35]}$

\section{DISCUSSION}

\section{A. Autonomous Repair of Creep Damage}

The fractographs of the creep rupture surface in Figure 3 indicate that intergranular failure is the dominant failure mode for this material. As indicated in Figures 1 and 2, creep failure occurs at a relatively high strain of about 60 pct. The electron microscopy images of Figures 4, 5, and 6 indicate that creep damage forms at (i) grain boundaries oriented perpendicular to the loading direction, (ii) grain boundaries oriented along the loading direction, (iii) grain-boundary triple points and finally, to a lower extent, at (iv) localized deformation bands inside the grains. The shape of the larger Mo-rich deposits clearly reflects the morphology of the creep cavities, demonstrating that site-selective deposition of the Mo-rich phase at free creep cavity surfaces.

In order to evaluate the kinetics of the self-healing process, it is essential to obtain the effective grain-boundary and volume diffusion coefficient for 


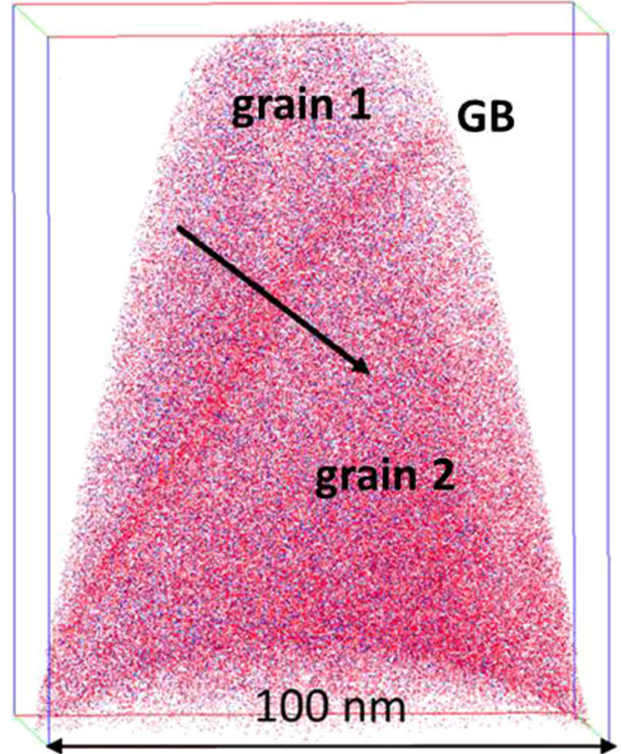

(a)

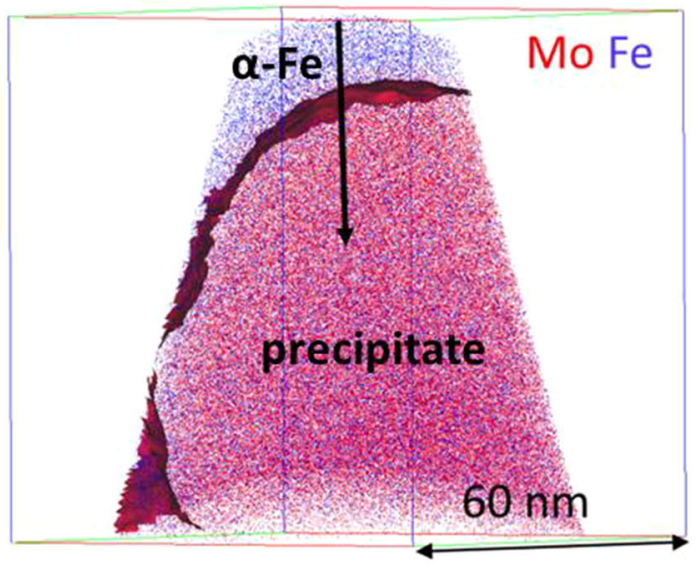

(c)

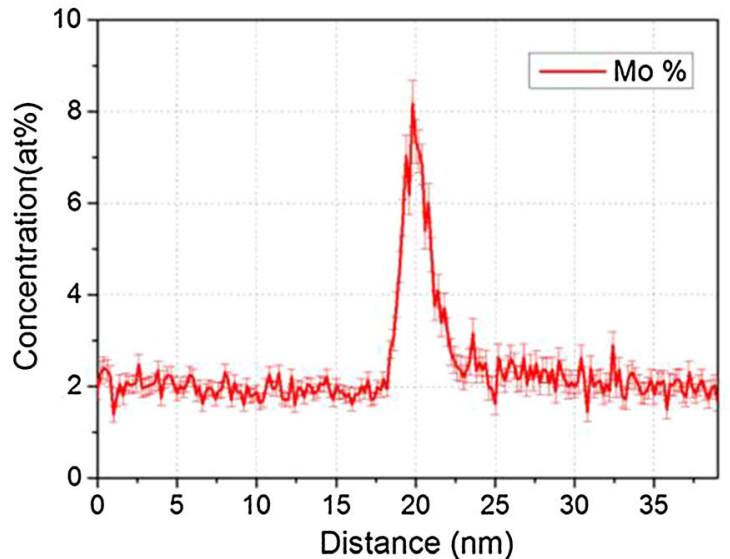

(b)

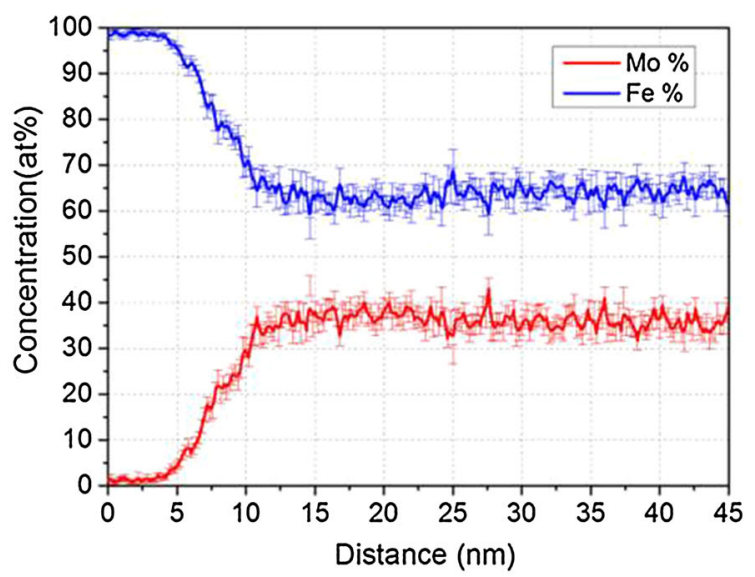

(d)

Fig. 9-Atom probe tomography data on the Fe-Mo alloy after creep at a stress of $180 \mathrm{MPa}$ at a temperature of $823 \mathrm{~K}\left(550{ }^{\circ} \mathrm{C}\right)$, showing $(a)$ a grain boundary (GB) with a Mo segregation of up to 8 at. pct $(b)$ and $(c)$ a Mo-rich particle at a grain boundary with a concentration of 36 at. pct Mo $(d)$. All elements except $\mathrm{Fe}$ (blue) and Mo (red) are removed for clarity (Color figure online).

Mo in the Fe matrix. As no information is available for the grain-boundary diffusion coefficient of Mo in pure iron, the $\mathrm{Fe}$ self diffusion along grain boundaries is applied. At $823 \mathrm{~K}\left(550{ }^{\circ} \mathrm{C}\right)$, which is in the middle of the explored temperature regime, the grain-boundary diffusivity in iron amounts to $D_{\mathrm{GB}}=2.4 \times 10^{-14} \mathrm{~m}^{2} \mathrm{~s}^{-1},[36]$ while the volume diffusivity of Mo in iron is estimated to be $D_{\mathrm{V}}=2.8 \times 10^{-21} \mathrm{~m}^{2} \mathrm{~s}^{-1[30]}$ Using the literature value for the volume diffusion coefficient of Mo in an iron matrix at $823 \mathrm{~K}\left(550^{\circ} \mathrm{C}\right)$ and a time to failure of 800 hours the estimated diffusion length amounts to $2 \sqrt{D_{\mathrm{V}} t} \approx 0.2 \mu \mathrm{m}$ for volume diffusion and $2 \sqrt{D_{\mathrm{GB}} t} \approx$ $500 \mu \mathrm{m}$ for grain-boundary diffusion. The large difference between the diffusion length and the Mo-depletion distance indicates that only a thin layer close to the grain boundaries will be solute-depleted. This is supported by the current atom probe results which indicate that the $\alpha$-Fe matrix further away from the grain boundaries still has the nominal composition. In previous experiments on $\mathrm{Fe}-\mathrm{Au}$ alloys, ${ }^{[21,22]}$ it was found that the value of the effective volume diffusion coefficient was three orders of magnitude larger than expected as a result of an extensive subgrain formation during creep loading. For the Fe-Mo alloy, the EBSD experiments did not show experimental evidence for extensive subgrain formation (Figure 7). The observed distance between the deformation bands in the Fe-Mo alloy is of the order of the grain size (see Figure 4), and therefore, the generated diffusion pathways are macroscopically spaced in the Fe-Mo alloy, while the diffusion pathways in the $\mathrm{Fe}-\mathrm{Au}$ alloy are spaced microscopically. As a result, these deformation bands are not expected to contribute significantly to the effective volume diffusion and the solute-depleted regions remain relatively narrow in the vicinity of the grain boundaries that act as fast diffusion pathways. 


\section{B. Requirements for the Healing of Creep Damage}

Our current experiments on the self-healing behavior of creep damage in $\mathrm{Fe}-\mathrm{Mo}$ alloys are in qualitative agreement with those obtained for the $\mathrm{Fe}-\mathrm{Au}$ alloy system. ${ }^{[21,22]}$ From these studies, the following requirements to achieve an efficient autonomous repair of creep damage can be formulated ${ }^{[37]}$ :

1. Mobile healing agent: high mobility of the segregating solute element.

2. Driving force toward the damage site:

a. Chemical potential provided by supersaturation of the chosen solute.

b. Gain in strain and surface energy for precipitates located at creep cavities.

3. Damage formation acts as a trigger for precipitation at the free surface of a damage site.

4. Site-selective precipitation: a high energy barrier for nucleation at nondamage sites.

5. Sufficient interfacial bonding between matrix and precipitate.

6. A high healing rate compared to the rate of damage formation.

7. Sufficiently large reservoir of healing agents within the matrix to heal the damage volume.

In the following, the estimation of the healing potential of local creep damage (i.e., open pores at grain boundaries) is discussed, given the available reservoir of healing agents (supersaturated solute). Furthermore, we will discuss the relative healing efficiency.

\section{Solute Reservoir for the Healing of Creep Damage}

If the filling (i.e., autonomous repair) of creep cavities is purely driven by the supersaturation of the solute Mo atoms, then it can easily be estimated how much damage can potentially be healed by balancing the volume fraction of grain-boundary creep cavities $f_{\mathrm{D}}$, with the volume fraction that can maximally be filled by the deposit formed by the supersaturated solute $f_{\mathrm{H}}$.

The volume fraction of creep damage can be estimated as $f_{\mathrm{D}}=N_{\mathrm{C}} V_{\mathrm{C}} / V_{\mathrm{G}}$, where $N_{\mathrm{C}}$ is the average number of grain-boundary creep cavities per grain, $V_{\mathrm{C}}$ is the average volume of a single creep cavity, and $V_{\mathrm{G}}$ is the average grain volume. For a lens-shaped creep cavity, one finds $V_{\mathrm{C}}=\pi \psi d_{\mathrm{C}}^{3} / 6$, where $d_{\mathrm{C}}$ is the cavity diameter and $\psi=\left(2-3 \cos \alpha+\cos ^{3} \alpha\right) / 2 \sin ^{3} \alpha \approx 0.69$ a geometrical factor that is defined by the opening angle $\alpha$ $\approx 75 \mathrm{deg}$ of the creep cavity. ${ }^{[38]}$ Assuming a spherical grain shape, the grain volume amounts to $V_{\mathrm{G}}=\pi d_{\mathrm{G}}^{3} / 6$, where $d_{\mathrm{G}}$ is the grain diameter. Combining these relations leads to

$$
f_{\mathrm{D}}=\psi N_{\mathrm{C}}\left(d_{\mathrm{C}} / d_{\mathrm{G}}\right)^{3}
$$

The volume fraction of creep damage that can maximally be healed by the supersaturated solute $f_{\mathrm{H}}$ can be evaluated from the initially homogeneously distributed nominal solute concentration $x_{0}(=3.7$ at . pct Mo for this alloy), the equilibrium solute concentration in the matrix $x_{\mathrm{m}}(=0.8$ at. pct Mo at $T=$ $\left.823 \mathrm{~K}\left(550^{\circ} \mathrm{C}\right)\right)$ and a scaling factor $R \approx 1$ for the effective volume occupied by the solute atom in the precipitate compared to its volume occupied in the solute:

$$
f_{\mathrm{H}}=R\left(x_{0}-x_{\mathrm{m}}\right)
$$

The scaling factor $R$ can be approximated by the difference in atomic volume occupied by the solute Mo relative to Fe: $R \approx v_{\mathrm{Mo}} / v_{\mathrm{Fe}}=1.30$. The maximum phase fraction of grain-boundary precipitates depends on the solute concentration in the precipitate $x_{\mathrm{p}}(=33.3$ at. pct $\mathrm{Mo}$ for the $\mathrm{Fe}_{2} \mathrm{Mo}$ precipitates) and amounts to $f_{\mathrm{p}}=\left(x_{0}-x_{\mathrm{m}}\right) / x_{\mathrm{p}}=9.3$ pct.

The consumed fraction of the healing reservoir $\chi$ can now be defined as follows:

$$
\chi=\frac{f_{\mathrm{D}}}{f_{\mathrm{H}}}=\left(\frac{\psi}{R}\right)\left(\frac{N_{\mathrm{C}}}{x_{0}-x_{m}}\right)\left(\frac{d_{\mathrm{C}}}{d_{\mathrm{G}}}\right)^{3} \leq 1
$$

Initially there is no damage, and therefore $\chi=0$. During creep, this value increases until the reservoir of supersaturated solute is depleted when a critical value of $\chi=1$ is reached. From Eq. [4], it can be seen that for a given type of healing precipitate, the critical value for which the solute reservoir is depleted is reached later when (i) the grains are larger, (ii) the supersaturation is higher, (iii) the creep cavities are smaller, and (iv) the number of creep cavities per grain is lower. As expected, the grain size and cavity size are the dominant contributions. For an average grain size of $d_{\mathrm{G}}=20 \mu \mathrm{m}$, a cavity size of $d_{\mathrm{C}}=1 \mu \mathrm{m}$ and a supersaturation of $\Delta x=$ $x_{0}-x_{\mathrm{m}}=3$ at. pct Mo about 450 cavities $\left(N_{\mathrm{C}}\right)$ can be filled at the grain boundary of a single grain before the supersaturation is exhausted $(\chi=1)$.

It should however be noted that the above discussion is only valid for long time scales. For creep experiments with a finite time, not all supersaturated solute may have had the time to diffuse toward the grain boundaries and contribute to the filling of the creep cavities. As discussed before, the estimated diffusion length within the grain amounts to $2 \sqrt{D_{V} t}$. The diffusion-limited volume fraction that can maximally be healed $f_{\mathrm{H}}^{\mathrm{kin}}$ is reduced to the fraction of the grain that is located within a diffusion length of the grain boundary:

$$
f_{\mathrm{H}}^{\mathrm{kin}}=f_{\mathrm{H}}\left\{1-\left(1-\frac{4 \sqrt{D_{\mathrm{V}} t}}{d_{\mathrm{G}}}\right)^{3}\right\} \approx f_{\mathrm{H}}\left(\frac{12 \sqrt{D_{\mathrm{V}} t}}{d_{\mathrm{G}}}\right)
$$

Only when the diffusion length $2 \sqrt{D_{\mathrm{V}} t}$ is larger than the grain radius $d_{\mathrm{G}} / 2$, all available solute reserves can contribute to pore filling, resulting in $f_{\mathrm{H}}^{\mathrm{kin}}=f_{\mathrm{H}}$. This situation is reached after a characteristic time of $t_{0}=$ $d_{\mathrm{G}}^{2} / 16 D_{V}$. Using the literature value for volume diffusion coefficient of Mo in bec Fe of $D_{V}=2.8 \times 10^{-21} \mathrm{~m}^{2} \mathrm{~s}^{-1}$ at $823 \mathrm{~K}\left(550^{\circ} \mathrm{C}\right)^{[30]}$ and a time to failure of 800 hours, the estimated diffusion length amounts to $2 \sqrt{D_{\mathrm{V}} t} \approx 0.2$ $\mu \mathrm{m}$. For a grain size of $d_{\mathrm{G}}=20 \mu \mathrm{m}$, the available solute is reduced by a factor $f_{\mathrm{H}}^{\mathrm{kin}} / f_{\mathrm{H}} \approx 12 \sqrt{D_{\mathrm{V}} t} / d_{\mathrm{G}}=6 \mathrm{pct}$, 


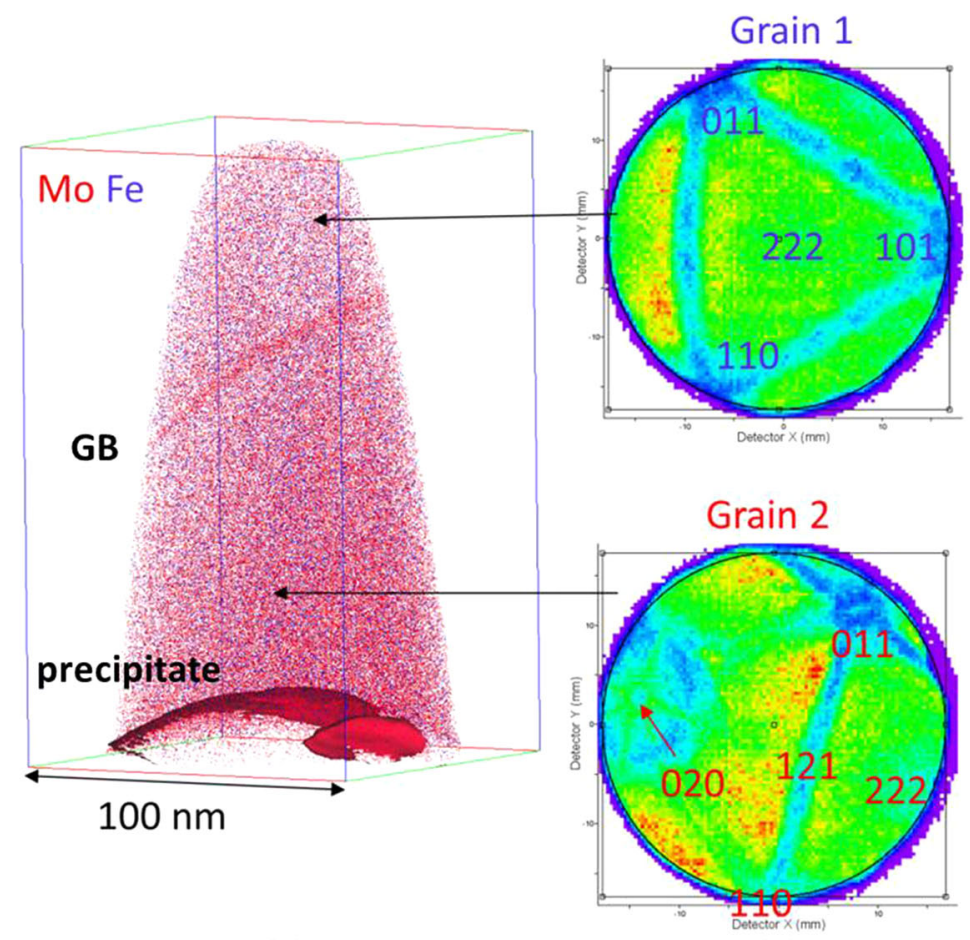

(a)

(b)

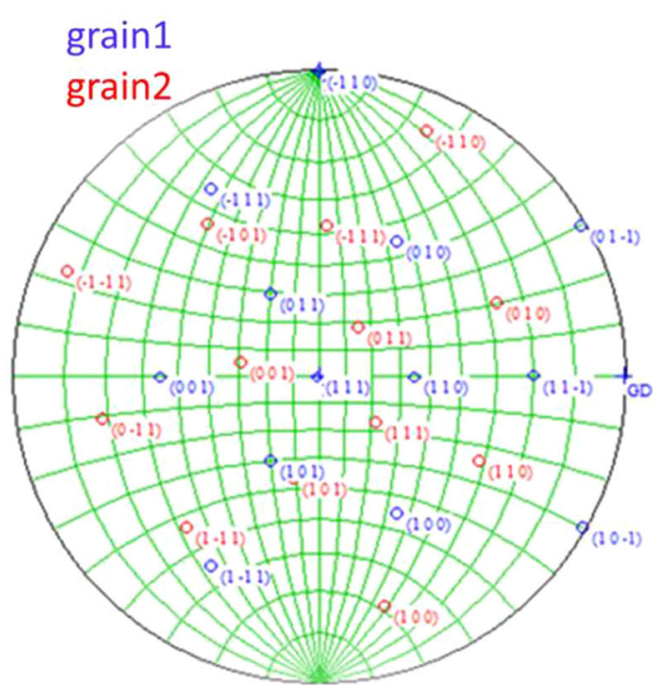

$[-0.648-0.281-0.708] 35.12^{\circ}$

Fig. 10-Atom probe crystallographic analysis of a grain boundary (GB); $(a)$ an ion map, containing a grain boundary, and a Mo-rich precipitate, highlighted by a 13 at. pct Mo isosurface; $(b)$ detector event histogram of the upper and lower grain with labeled crystallographic poles; $(c)$ standard stereographic projection, showing the poles of both grains. The grain-boundary disorientation was calculated using the TOCA software (Tools for Orientation Determination and Crystallographic Analysis). ${ }^{[39,40]}$

which means that the quoted maximum number of cavities per grain $\left(N_{\mathrm{C}}\right)$ that can be healed reduces from 450 to about 30 under the given conditions.

For the kinetically limited regime, the maximum number of cavities that can be healed now scales as $N_{\mathrm{C}}^{\max }(t) \propto \sqrt{t}$. For steady-state creep, the number of cavities per grain $N_{\mathrm{C}}(t)=\dot{N}_{\mathrm{C}} t$ however scales linearly with time. As a result, the part of the reservoir accessible by diffusion may potentially run out (when $t_{1}<t_{0}$ ) before all supersaturated solute is consumed, which then provides a limit on the maximum allowed strain rate to provide efficient filling of the cavities.

\section{Healing Efficiency of Creep Damage}

The previously developed model for the filling of creep cavities ${ }^{[22]}$ will be used to estimate the average filling ratio $\eta$ of creep cavities as a function of (increasing) applied stress (or decreasing failure time). It is assumed that the site-selective precipitation at the cavities starts immediately after the nucleation of creep cavities. The lifetime generally scales with the applied stress $\sigma$ as: $t_{f}=k \sigma^{-n}$, where $k$ is a temperature-dependent constant and, as discussed in "Section III," the stress exponent amounts to $n \approx 15$ for the Mo alloy.

The healing time $t_{h}$ can be evaluated by assuming a time-dependent creep cavity volume of $V_{\mathrm{c}}(t)=V^{*}+$ $a \sigma t$ and a precipitate volume of $V_{\mathrm{p}}(t)=b t$. The time to fill an individual creep cavity $t_{\mathrm{h}}=\left(V^{*} / b\right) /\left\{1-\sigma / \sigma_{\mathrm{c}}\right\}$ now strongly depends on the applied stress, where $\sigma_{\mathrm{c}}=b / a$ is the critical stress beyond which the cavity grows faster than the filling takes place. ${ }^{[22]}$ The corresponding volume of the filled cavity is $V_{\mathrm{h}}=b t_{\mathrm{h}}=$ $V^{*} /\left\{1-\sigma / \sigma_{c}\right\}$. The fraction of filled cavities now amounts to

$$
\eta \approx \frac{t_{\mathrm{f}}-t_{\mathrm{h}}}{t_{\mathrm{f}}}=1-\left(\frac{V^{*}}{b k}\right) \frac{\sigma^{n}}{1-\sigma / \sigma_{\mathrm{c}}}
$$

Although the critical stress is expected to be beyond $200 \mathrm{MPa}$, the high value for the stress exponent $n \approx 15$ clearly limits the expected stress range for which filling of the creep cavities by Mo precipitates is effective at a given temperature.

\section{E. Effect of Autonomous Creep Cavity Filling on the Macroscopic Creep Behavior}

It is not straightforward to quantify the effect of healing on the overall creep behavior experimentally. The best would be to have a reference sample that is not self-healing, but has comparable creep properties. In a previous paper, we established that self-healing extends the lifetime by using both solutionized and solution-depleted $\mathrm{Fe}-\mathrm{Cu}$ alloys as reference system for the studied $\mathrm{Fe}-\mathrm{Au}$ alloys. ${ }^{[21,22]}$ In these experiments, it was found that the filling of creep cavities significantly reduces the strain rate. The same mechanisms are expected to apply for creep in Fe-Mo alloys. More experimental and modeling studies are required to establish the link 
between the microscopic creep cavity filling and the macroscopic creep rate in detail.

\section{CONCLUSIONS}

We have studied the self-healing potential of creepinduced defects in a high-purity $\mathrm{Fe}-\mathrm{Mo}$ alloy (6.2 wt pet Mo) at temperatures of $813 \mathrm{~K}, 823 \mathrm{~K}$, and $838 \mathrm{~K}\left(540{ }^{\circ} \mathrm{C}, 550{ }^{\circ} \mathrm{C}\right.$, and $\left.565^{\circ} \mathrm{C}\right)$. The creep curves at different constant stresses indicate a ductile fracture mode with maximum strains up to 60 pct. Electron microscopy measurements after creep clearly indicate a filling of creep cavities by $\mathrm{Fe}_{2} \mathrm{Mo}$ precipitates. In some cases, a partial filling of the creep cavities is observed, while in most cases a complete filling is found. The presence of relatively large precipitates with irregular shapes indicates a filling of the creep cavities. The density of generated cavities and the formed precipitates strongly increases with the temperature. As a result of the relatively large strain at rupture, creep cavities are formed not only at grain boundaries oriented perpendicular to the loading direction and at triple points, but also at sliding grain boundaries oriented along the loading direction.

The demonstrated site-selective $\mathrm{Fe}_{2} \mathrm{Mo}$ precipitation at creep cavity surfaces provides the opportunity to incorporate self-healing capabilities in high-temperature creep steels that often already contain Mo for solid-solution strengthening. Supersaturation of Mo in the alloy can provide a desirable self-healing healing potential to further extend the creep lifetime. Achieving this requires a careful design of the alloy composition and heat treatment. Considering the solubility of $1.4 \mathrm{wt}$ pct Mo for binary $\mathrm{Fe}-\mathrm{Mo}$ at $823 \mathrm{~K}\left(550{ }^{\circ} \mathrm{C}\right)$, the Mo concentration can probably be reduced to about 3 wt pet Mo (about 1 at. pct supersaturation) without sacrificing the healing capabilities.

\section{ACKNOWLEDGMENTS}

This research was financially supported by the innovation-oriented research program (IOP) on self-healing materials of the Dutch Ministry of Economic Affairs, Agriculture and Innovation (IOP project SHM01017). We thank Marcel Sluiter and Casper Versteylen for their fruitful discussions and Gijs Langelaan for assistance with the development of the creep tester.

\section{OPEN ACCESS}

This article is distributed under the terms of the Creative Commons Attribution 4.0 International License (http://creativecommons.org/licenses/by/4.0/), which permits unrestricted use, distribution, and reproduction in any medium, provided you give appropriate credit to the original author(s) and the source, provide a link to the Creative Commons license, and indicate if changes were made.

\section{REFERENCES}

1. R.L. Klueh: Mater. Sci. Eng., 1978, vol. 35, pp. 239-53.

2. R.L. Klueh: Nucl. Eng. Des., 1982, vol. 72, pp. 329-44.

3. T. Sourmail: Mater. Sci. Techn., 2001, vol. 17, pp. 1-14.

4. A. Fuchs and B. Ilschner: Acta Metall., 1969, vol. 17, pp. 701-10.

5. H. Oikawa, D. Mizukoshi, and S. Karashima: Metall. Trans. A, 1978, vol. 9A, pp. 1281-85.

6. H. Oikawa, K. Kaneko, and S. Hasegawa: Scripta Metall., 1984, vol. 18, pp. 393-96.

7. S. Nanba and H. Oikawa: Mater. Sci. Eng. A, 1988, vol. 101, pp. 31-37.

8. E. Hornbogen: J. Appl. Phys., 1961, vol. 32, pp. 135-39.

9. D. Isheim: Acta Mater., 2000, vol. 48, pp. 2873-83.

10. J. Hald: Int. J. Pres. Vessels Pip., 2008, vol. 85, pp. 30-37.

11. S. Zhu, M. Yang, X.L. Song, Z. Zhang, L.B. Wang, S. Tang, and Z.D. Xiang: Mater. Sci. Eng. A, 2014, vol. 619, pp. 47-56.

12. K. Laha, J. Kyono, S. Kishimoto, and N. Shinya: Scripta Mater., 2005, vol. 52, pp. 675-78.

13. K. Laha, J. Kyono, and N. Shinya: Scripta Mater., 2007, vol. 56, pp. 915-18.

14. K. Laha, J. Kyono, and N. Shinya: Philos. Mag., 2007, vol. 87, pp. $2483-2505$.

15. K. Laha, J. Kyono, and N. Shinya: Metall. Mater. Trans. A, 2011, vol. 43A, pp. 1187-97.

16. S.M. He, N.H. van Dijk, H. Schut, E.R. Peekstok, and S. van der Zwaag: Phys. Rev. B, 2010, vol. 81, p. 094103.

17. S.M. He, N.H. van Dijk, M. Paladugu, H. Schut, J. Kohlbrecher, F.D. Tichelaar, and S. van der Zwaag: Phys. Rev. B, 2010, vol. 82, p. 174111

18. S. Zhang, J. Kohlbrecher, F.D. Tichelaar, G. Langelaan, E. Brück, S. van der Zwaag, and N.H. van Dijk: Acta Mater., 2013, vol. 61, pp. 7009-19.

19. S. Zhang, H. Schut, J. Č́žzek, F.D. Tichelaar, E. Brück, S. van der Zwaag, and N.H. van Dijk: J. Mater. Sci., 2014, vol. 49, pp. $2509-18$

20. S. Zhang, G. Langelaan, J.C. Brouwer, W.G. Sloof, E. Brück, S. van der Zwaag, and N.H. van Dijk: J. Alloys Comp., 2014, vol. 584 , pp. $425-29$.

21. S. Zhang, C. Kwakernaak, W.G. Sloof, E. Brück, S. van der Zwaag, and N.H. van Dijk: Adv. Eng. Mater., 2015, vol. 17, pp. 598-603.

22. S. Zhang, C. Kwakernaak, F.D. Tichelaar, W.G. Sloof, M. Kuzmina, M. Herbig, D. Raabe, E. Brück, S. van der Zwaag, and N.H. van Dijk: Metall. Mater. Trans. A, 2015, vol. 46A, pp. $5656-70$.

23. K. Thompson, B. Gorman, D.J. Larson, B. van Leer, and L. Hong: Microsc. Microanal., 2006, vol. 12, pp. 1736-37.

24. B.P. Geiser, D.J. Larson, E. Oltman, S. Gerstl, D. Reinhard, T.F. Kelly, and T.J. Prosa: Microsc. Microanal., 2009, vol. 15, pp. 292-93.

25. M.J. Luton and C.M. Sellars: Acta Metall., 1969, vol. 17, pp. $1033-43$.

26. T. Sakai and J.J. Jonas: Acta Metall., 1984, vol. 32, pp. 189-209.

27. F. Otto, G.B. Viswanathan, E.J. Payton, J. Frenzel, and G. Eggeler: Acta Mater., 2012, vol. 60, pp. 2982-98.

28. O.D. Sherby: Acta Metall., 1962, vol. 10, pp. 135-47.

29. S. Spigarelli, L. Kloc, and P. Bontempi: Scripta Mater., 1997, vol. 37, pp. 399-404.

30. H. Nitta, T. Yamamoto, R. Kanno, K. Takasawa, T. Iida, Y. Yamazaki, S. Ogu, and Y. Iijima: Acta Mater., 2002, vol. 50, pp. 4117-25.

31. T.B. Massalski, H. Okamoto, P.R. Subramanian, and L. Kaeprzak: Binary Alloy Phase Diagrams, 2nd ed., ASM International, Materials Park, 1990.

32. B.W. Krakauer and D.N. Seidman: Phys. Rev. B, 1993, vol. 48, pp. $6724-27$. 
33. M.P. Moody, F. Tang, B. Gault, S.P. Ringer, and J.M. Cairney: Ultramicroscopy, 2011, vol. 111, pp. 493-99.

34. P. Lejček, S. Hofmann, and V. Paidar: Acta Mater., 2003, vol. 51, pp. 3951-63.

35. M. Herbig, D. Raabe, Y.J. Li, P. Choi, S. Zaefferer, and S. Goto: Phys. Rev. Lett., 2014, vol. 112, p. 126103.

36. G. Stechauner and E. Kozeschnik: J. Mater. Eng. Perform., 2014, vol. 23, pp. 1576-79.
37. Self Healing Materials: Pioneering research in the Netherlands, 2nd ed., S. Zwaagvan der, and E. Brinkman, eds., Self Healing Materials: Pioneering research in the Netherlands, IOS Press, Amsterdam, 2015.

38. R. Raj and M.F. Ashby: Acta Metall., 1975, vol. 23, pp. 653-66. 39. S. Zaefferer: Adv. Imag. Electron Phys., 2002, vol. 125, pp. 355-415.

40. S. Zaefferer: J. Appl. Crystallogr., 2000, vol. 33, pp. 10-25. 